\title{
A Proposed Knowledge Management Implementation Framework for the Ghanaian Construction Industry
}

\author{
Francis Lanme Guribie1, Callistus Tengan² \\ ${ }^{1}$ Department of Building Technology, Tamale Technical University, Tamale, Ghana \\ ${ }^{2}$ Department of Building Technology, Bolgatanga Polytechnic, Bolgatanga, Ghana \\ Email:2fgrubie@gmail.com, callyclarke@gmail.com
}

How to cite this paper: Guribie, F.L. and Tengan, C. (2019) A Proposed Knowledge Management Implementation Framework for the Ghanaian Construction Industry. Journal of Building Construction and Planning Research, 7, 1-10.

https://doi.org/10.4236/jbcpr.2019.71001

Received: September 24, 2018

Accepted: January 15, 2019

Published: January 18, 2019

Copyright ( 2019 by author(s) and Scientific Research Publishing Inc. This work is licensed under the Creative Commons Attribution International License (CC BY 4.0).

http://creativecommons.org/licenses/by/4.0/

\begin{abstract}
This study aims at developing a Knowledge Management Implementation Framework for adoption by firms in the Ghanaian construction industry. Recent developments in the field of Knowledge management in the construction sector have led to a renewed competition in driving organizational performance. However, the construction industry in Ghana lacks a knowledge management implementation framework that addresses the needs of the Ghanaian construction supply chain while a comprehensive approach to managing knowledge remains nebulous. The study adopted an extensive literature review of existing knowledge management models to provide the basis for the development of the proposed framework for Ghana. The proposed knowledge management implementation framework was subjected to testing and validation by project managers drawn from nineteen indigenous construction firms in Ghana. The technology acceptance model (TAM) was used as the criteria to validate the proposed knowledge management implementation framework. The proposed Guribie \& Tengan knowledge management implementation framework was perceived to be useful, and easy to use and the intention to adopt and use was high among indigenous Ghanaian construction firms. The study recommends further validation using wider population to enhance the efficacy of the framework for wider industry acceptance to enhance organizational competitiveness and performance delivery.
\end{abstract}

\section{Keywords}

Construction, Ghana, Implementation Framework, Knowledge Management, Technology Acceptance Model (TAM) 


\section{Introduction}

Knowledge management is a key tool in the construction industry to drive competitive advantage [1] [2]. The emergence of knowledge management in this function poses a challenge to construction firms to formally manage knowledge generated to their advantage [1]. Egbu, Hari, and Kumar [3] reaffirm that, construction firms having been managing knowledge informally now need a more structured and coherent approach to sustain competitive advantage. Nonetheless, [4] argued that a comprehensive way to manage knowledge towards maximizing returns on investment remains vague. Likewise, the success from $\mathrm{KM}$ is hinged on the effective and efficient disposition of various knowledge management strategies and tools within the context of specific organizations [5]. The process of improving this organization capability should begin with an in-depth understanding and evaluation of a firm's knowledge management practices. While knowledge management has made surge globally and in developed economies such as the UK construction industry [6], formal knowledge management implementation in Ghana is at infancy with no implementation frameworks for adoption by firms in the construction sector. The study in advocating for the implementation of knowledge management in the Ghanaian construction industry, a preliminary knowledge management implementation framework is developed for construction organizations in Ghana to adopt particularly indigenous and small-scale firms to improve overall business performance and drive competitive advantage. The management of knowledge in this regard is at four levels which include management of project knowledge; individual knowledge; organization knowledge; and environmental knowledge.

\section{Information and Knowledge Management in Construction}

The construction industry is a project-based industry. The projects are one-off and usually custom built to clients' specification. In construction, problem-solving often takes place in a team environment [7]. During the shared problem solving, stakeholders bring different types of knowledge into the problem situation and it is captured, created and shared by team members [8]. For such a problem-solving to become a true innovation, the solutions reached for particular problems should be learned, codified and applied to future projects [9]. In a bid to manage construction knowledge, the nature and type of knowledge must be explained. As stated earlier, the management of knowledge in construction firms is at four levels which include management of project knowledge; individual knowledge; organization knowledge; and environmental knowledge. Personal knowledge can become organizational knowledge through the dynamic interaction between tacit knowledge and explicit knowledge. This dynamic process is the essence of knowledge creation in an organization ([10] p. 6). On the contrary, organizational knowledge can become personal knowledge through the process of internalization. This involves developing new experiences by learning from, re-using and re-applying the existing explicit knowledge to produce new tacit knowledge. 
Furthermore, lessons learnt from individual projects must be externalized to become organizational knowledge. Through externalization, a senior engineer can translate his tacit knowledge such as experiences, ideas, know-how and perceptions into explicit knowledge in the form of reports, specifications, articles, procedures, descriptions etc. In conclusion, the best practices from the wider construction environment must be incorporated into individual organizations to enhance overall business performance.

\subsection{Knowledge Management Implementation Challenges}

The process of KM is confronted with diverse challenges, making knowledge management a difficult task to implement [11]. Most of the barriers are identified as human-centred. Research conducted by Carillo, Robinson, Al-Ghassani, and Anumba [12] on construction organisations reveals four (4) main barriers in implementing an effective KM strategy. They include organisational culture, lack of standard work process, lack of funding and lack of time. Dainty, Bryman, and Price [13] also identified three (3) barriers which are; poor culture, ineffective communication structure and time constraints in the organization. Similarly, Robinson, Carillo, Anumba, and Al-Ghassani [14] identified poor culture, time constraints, poor standard work processes, poor IT infrastructure etc. as major barriers to KM implementation. The enormous potential of the Ghanaian construction industry towards national development makes institutionalizing knowledge management practice imperative particularly by indigenous construction firms. Yet, implementation of KM in the Ghanaian construction industry has met several challenges and resulted in the poor KM practice. Hackman, Agyekum, Smith [15], avers that the absence of KM systems, lack of leadership support and the poor awareness of KM practices are the major knowledge management implementation challenges in the Ghanaian construction industry. Similarly, with the construction industry characterized as an infant industry in the adoption of KM practice, Asoh, Belardo, and Neilson [16], avers that the lack of time and management support in institutionalizing KM in new economies. The industry's output is reliant on multilevel activities and work processes which involve professionals, skilled and unskilled workforce as well as several interlinked departments thereby reinforcing the need for knowledge sharing and management to upscale industry performance. Hence, the current study seeks to propose a KM implementation framework for the Ghanaian construction industry to optimize the project delivery process.

\subsection{Knowledge Management Frameworks}

In this section, some recent research into knowledge management for the construction industry is reviewed. A critical review is conducted on existing of $\mathrm{KM}$ frameworks to provide a sound theoretical basis for the development of KM implementation framework for adoption by firms in the Ghanaian construction industry. According to Kuan and Elaine [17], developing a KM implementation 
framework is the initial stage of any initiative to implement KM. The study aims at identifying and filling in the gap of existing frameworks and highlighting distinctive factors that suit the Ghanaian construction supply chain. A proposed KM implementation framework by Wetherall, Rezgui, Lima, and Zarli [18] in the e-COGNOS project aims at promoting KM within the collaborative construction environment. This framework is in a cycle of eight phases (see Figure 1). In this KM framework, the initial phase of project preparation aims at preparing the prospective user organization for the knowledge management project. The framework also highlights the core business competence by appraising KM tools and environmental enablers which are critical success factors for effective $\mathrm{KM}$ implementation. By focusing on a specific business unit of the organisation through a case study approach, the framework addresses specific knowledge management needs of the organization. Finally, this framework proposes a measurement system for strategizing and evaluation on the overall business performance.

This framework, however, is too generic and not detailed for infant knowledge management organizations. It fails to capture the types of knowledge and the processes and tools of converting them into organizational knowledge. Furthermore, it fails to take into account the differences in the various construction supply chains and their uniqueness. It also fails to take into account quality management of the various processes.

Figure 2 presents the steps in the knowledge transfer process in a knowledge transfer-enabling environment developed by [19]. The framework proposes seven (7) KM processes which require four (4) environmental enablers to function effectively. An enabling KM culture, technology, infrastructure and periodic measurement promote knowledge management. Irrespective of the gaps filled by this framework, it also fails to differentiate the types of knowledge; thus, tacit

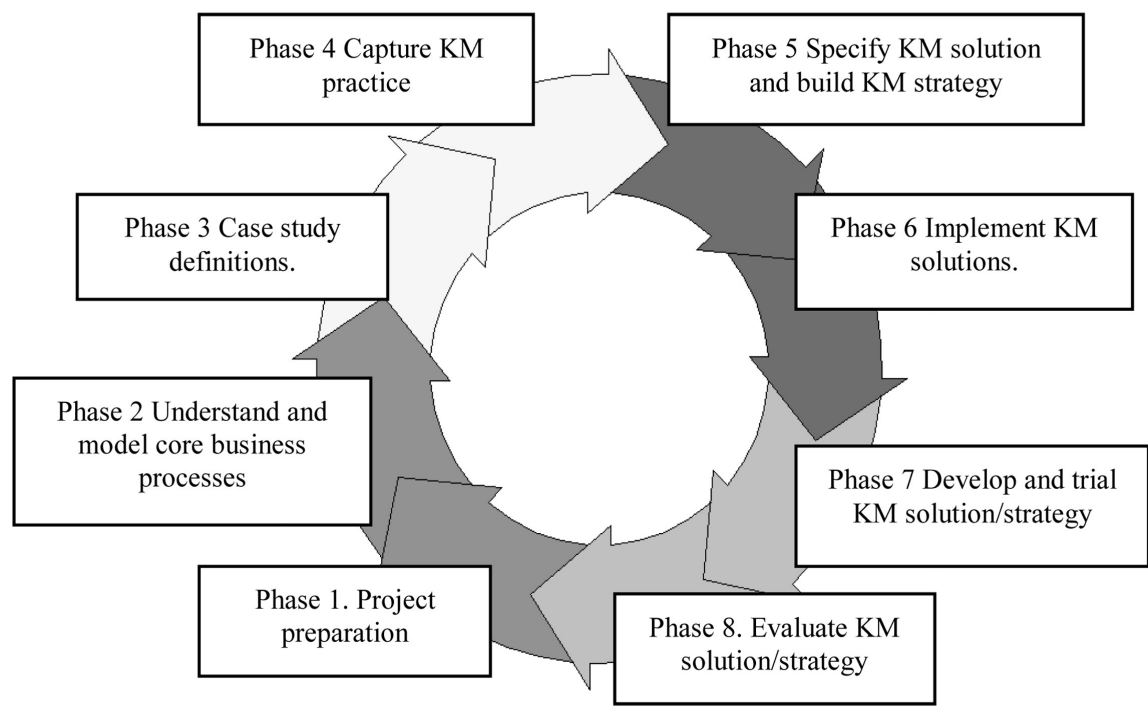

Figure 1. The e-COGNOS methodology. Source: Wetherall, Rezgui, Lima, and Zarli (2002). 


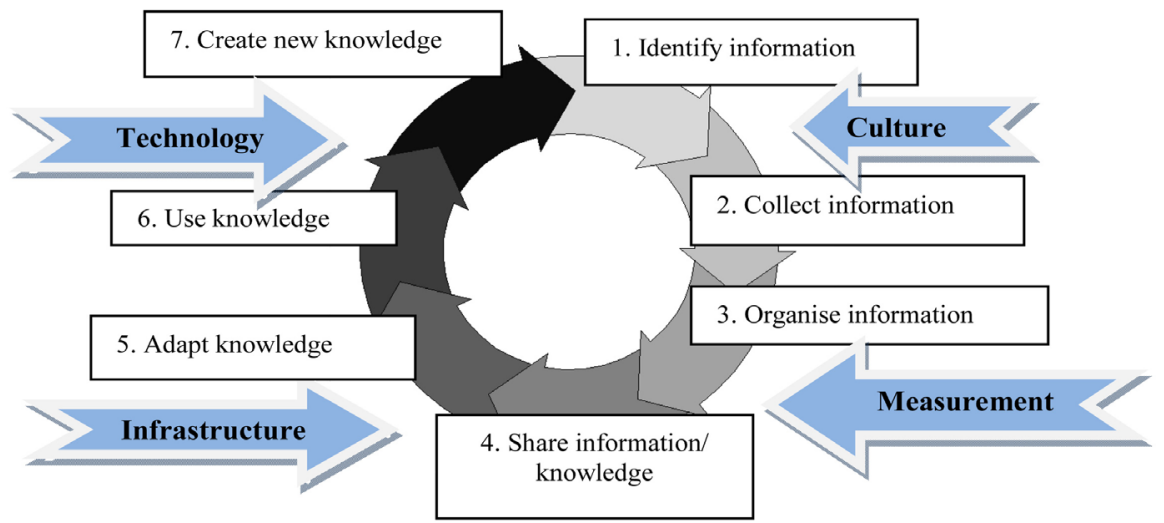

Figure 2. Steps in the knowledge transfer process in a knowledge transfer-enabling environment. Source: O’Dell, and grayson (1998).

and explicit. The framework highlights knowledge transfer processes and the enabling environmental factors. Thus, it is process oriented with little emphasis on the different methods and tools in knowledge conversion.

\section{Research Methodology}

The study adopted an extensive literature review approach by critiquing existing knowledge management frameworks/models from other industries and organizations which provided the basis for the development of the Guribie-Tengan knowledge management implementation framework (KMIF) for the Ghanaian construction industry. Literature on Information and Knowledge Management in Construction, KM implementation challenges and KM frameworks were reviewed to underpin the development of the proposed integrated KM implementation framework. In an earlier study by Guribie, Tengan, and Kuebutornye [20], the study recommended the development of a KM framework for adoption by Ghanaian construction firms due to the apparent lack of an existing KM framework in the Ghanaian construction industry. Based on the findings from literature and existing empirical data, a preliminary knowledge management implementation framework is developed. The proposed Guribie-Tengan KMIF was subjected to testing and validation by project managers drawn from nineteen indigenous construction firms in Ghana. The Technology Acceptance Model (TAM) by Venkatesh and Davis [21] was used as the criteria to validate the proposed Guribie-Tengan KMIF. The Technology Acceptance Model has widely been accepted for use to determine whether a technology may be accepted or rejected [21]. The project managers were presented with the proposed Guribie-Tengan KMIF with explanatory notes and were required to rate on a five-point Likert scale the extent to which the proposed KMIF is perceived to be useful, easy to use and the intention to adopt and use the framework

\section{Developing the Guribie-Tengan Knowledge Management Implementation Framework}

Developing the Guribie-Tengan KMIF relied greatly on the weaknesses of exist- 
ing frameworks that were reviewed, and the $\mathrm{KM}$ implementation challenges faced by the construction industry in Ghana. From the literature review undertaken, Knowledge management practice in the Ghanaian construction industry was found to be at its infancy stage [18]. Similarly, construction firms in Ghana were not aware of formal knowledge management and do not have formal KM strategies [19]. These findings corroborate the findings of a study conducted by Mpofu [22] in the Malawian construction firms where about half of the firms studied did not have a formal KM strategy in place.

Again, in a study conducted by Guribie, et al. [20], where KM tools and enablers were evaluated in four construction organizations, findings revealed a poor $\mathrm{KM}$ infrastructure by the organizations. Likewise, performance appraisal, documentation and codification of problem solutions and expertise of staff generally had low approval ratings, highlighting the fact that, there is no formal knowledge management in the firms. This notwithstanding, the organizations were committed to mentoring of junior staff, collaboration and teamwork which is characteristic of construction firms indicating some kind of informal knowledge management. The Guribie-Tengan KMIF is in Figure 3.

\section{Description of the Proposed Guribie-Tengan KM Implementation Framework}

To attain its final objective, the study proposes the Guribie-Tengan Knowledge management implementation framework for adoption by the construction industry firms for their initial knowledge management initiatives. The framework is a preliminary framework developed based on the extensive review of knowledge management studies and existing frameworks. The Guribie-Tengan knowledge management implementation framework discovers the prioritization of knowledge management as a strategic objective as the first initiative of KM implementation by firms in Ghana. It thus starts by emphasizing the need for construction firms in Ghana to incorporate $\mathrm{KM}$ as a strategic objective into their overall business strategy. Also, based on existing knowledge management methods, techniques and tools, the firms must rigorously follow five (5) knowledge management implementation processes in any knowledge management initiative. The processes include identifying and creating knowledge, capturing and storing the knowledge, transferring and sharing the knowledge, applying the acquired knowledge, and creating knew knowledge. Finally, the framework re-affirms the creation of an enabling environment as the fourth prerequisite component for an effective knowledge management implementation. It thus stresses on the importance of a knowledge management culture, infrastructure, technology, and periodic KM assessment/measurement.

\subsection{Testing and Validating the Proposed Guribie-Tengan KM Implementation Framework}

The preliminary framework was tested and validated to obtain feedback from 


\section{INCORPORATE KM AS STRATEGIC OBJECTIVE INTO OVERALL BUSINESS STRATEGY}

\section{KM PROCESSES}

2. IDENTIFY/ CREATE KNOWLEDGE

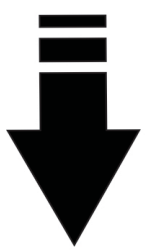

3. CAPTURE AND STORE

KNOWLEDGE IN

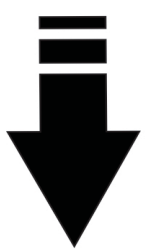

4. KNOWLEGE

TRANSFER/

SHARING FROM

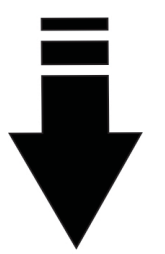

5. KNOWLEDGE

ACQUISITION/

APPLICATION

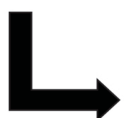

\section{KM METHODS/ TOOLS}

IIE) Brainstorming

Learning and capture

Communities of practice

Project design

Problem solutions

Expert advice

\section{ENVIRONMENTAL ENABLERS}

\section{KM Culture}

Documentation of problem solution Collaboration and teamwork Mentoring and coaching staff Training and staff development

\section{KM infrastructure}

$R$ \& $D$ unit

Formal KM department

Company library

Knowledge map

Communities of practice

\section{KM Technology}

Document management system

Collaboration systems

Communication facilities

Figure 3. Guribie-Tengan KMIF (2018).

\section{CREATE NEW KNOWLEDGE}

KM Measurement

Use KM tools to assess

company;s knowledge

management maturity levels

the users regarding the acceptance or operation of the framework. The framework was tested and validated against the criteria set out in the technology acceptance model (TAM) postulated by Venkatesh and Davis [21]. The Technology Acceptance Model has been described as the most parsimonious and widely used model that seeks to explain why a technology may be accepted or rejected 
[21]. The model argues that for the effective adoption of a framework such as the KMIF in the Ghanaian construction industry, the perceive usefulness of the framework, perceived ease of use and the intention of stakeholders to use or adopt the framework is imperative. Table 1 provides the rating on the statements for the testing and validation of the proposed Guribie \& Tengan KMIF. They are the perceive usefulness, perceive ease of use and the intention to use or adopt the KMIF. According to Davis [23], perceived usefulness describes the likelihood that the use of proposed KMIF will improve knowledge management processes and adoption in the firm. The extent to which project managers perceived the KMIF as useful recorded a mean score of 3.95 indicating high agreement of the usefulness of the proposed KM implementation framework. Similarly, the perceived ease of use denotes to the degree to which the potential user expects the KMIF to be effortless [23]. Responses indicated that, the percieved ease of use recorded a mean score of 4.11 while the intention to use or adopt the Guribie-Tengan KMIF recorded a mean score of 4.16. Having achieved mean scores greater than 3.5 ( $M S>3.5)$ for all the test criterial informs adoptability of the proposed Guribie-Tengan KMIF by contractors in the Ghanaian construction industry.

\subsection{Conclusions}

$\mathrm{KM}$ has been acknowledged as a strategic objective that requires to be incorporated in industry and organisations strategy towards achieving competiveness and enhance project performance. KM implementation by firms will facilitate stakeholder involvement and participation in the organisational structure and the day-to-day activities of the organisation to ensure key design and project implementation teams from top management down to middle level and unskilled labor is knowledgeable about best construction methods and practices. Knowledge created, stored and shared provides historical knowledge and information for future project delivery in the organisations. This paper presents the Guribie-Tengan knowledge management implementation framework tailored specifically to the needs of the construction industry in Ghana but can be adopted by other industries with similar characteristics. This new framework simplifies the process of knowledge management by reviewing the limitations of

Table 1. Test and validation of Guribie-Tengan KMIF.

\begin{tabular}{ccccc}
\hline Statements & N & $\begin{array}{c}\text { Mean } \\
\text { Score }\end{array}$ & Median & $\begin{array}{c}\text { Std. } \\
\text { Dev }\end{array}$ \\
\hline $\begin{array}{c}\text { To what extent do you perceive } \\
\text { the KMIF as useful? }\end{array}$ & 19 & 3.95 & 4.00 & 0.780 \\
$\begin{array}{c}\text { To what extent do perceive the } \\
\text { KMIF as easy to use? }\end{array}$ & 19 & 4.11 & 4.00 & 0.737 \\
$\begin{array}{c}\text { To what extent do you intend to } \\
\text { use or adopt the KMIF? }\end{array}$ & 19 & 4.16 & 4.00 & 0.765 \\
\hline
\end{tabular}

Source: SPSS output. 
existing frameworks and filling in the gaps of existing frameworks. The advantages of the framework are summarized below;

1) The Guribie-Tengan KMIF prioritizes knowledge management as a strategic objective and a critical initiative for adopting KM in Ghana.

2) The Guribie-Tengan KMIF is useful and easy to use by infant KM organizations such as the construction sector in Ghana.

3) In this framework, $\mathrm{KM}$ is seen as an embodiment of five (5) variables. These variables include KM strategy, KM processes, KM methods/tools, knowledge conversion and environmental enablers.

4) The Guribie-Tengan KMIF has overcome the shortcomings of existing frameworks which limit knowledge management to KM processes and enablers. For example, users are presented with the tools and methods of knowledge conversion in this framework.

The study recommends that further studies be conducted to further develop and modify the Guribie-Tengan KMIF for greater efficiency and effective implementation.

\section{Conflicts of Interest}

The authors declare no conflicts of interest regarding the publication of this paper.

\section{References}

[1] Preece, C., Moodley, K. and Hyde, J. (2000) Knowledge Management Strategies to Improve Construction Business Development Processes: A Preliminary Case Study. 16th Annual ARCOM Conference, Vol. 1, Glasgow, 6-8 September 2000, 325-34.

[2] Bratić, D. (2009) Knowledge and Knowledge Management as a Competitive Advantage. Acta Graphica, 20, 43-49.

[3] Egbu, C.O., Hari, S. and Kumar, B. (2004) Knowledge Capture in Small and Medium Enterprises in the Construction Industry: Challenges and Opportunities. 20 th Annual ARCOM Conference, Edinburgh, 1-3 September 2004, 847-855.

[4] Kluge J., Stein W., Licht T. and Bendler A. (2001) Knowledge Unplugged: The McKinsey \& Company Global Survey on Knowledge Management. Palgrave, Basingstoke. https://doi.org/10.1057/9780333977057

[5] Udeaja C.E, Kamara J.M. and Carrillo P.M. (2008) A Web-Based Prototype for Live Capture and Reuse of Construction Project Knowledge. Journal of Automation in Construction, 17, 839-851. https://doi.org/10.1016/j.autcon.2008.02.009

[6] Graham, B. and Thomas, K. (2005) An Investigation into the Development of Knowledge Management Systems within the Leading Irish Construction Companies. 21 st Annual ARCOM Conference, London, 7-9 September 2005, 499-508.

[7] Anumba, C.J., Ugwu; O.O., Newnham, L. and Thorpe, A. (2001) A Multi-Agent System for Distributed Collaborative Design. Logistics Information Management, 14, 355-366. https://doi.org/10.1108/EUM0000000006247

[8] Senaratne, S. and Sexton, M. (2008) Managing Construction Project Change: A Knowledge Management Perspective. Construction Management and Economics, 26, 1303-1311. https://doi.org/10.1080/01446190802621044 
[9] Sexton, M. and Barret, P.S. (2003) A Literature Synthesis of Innovation in Small Construction Firms: Insights, Ambiguities and Questions. Construction Management and Economics, 21, 613-622. https://doi.org/10.1080/0144619032000134147

[10] Uriarte, F.A. (2008) Introduction to Knowledge Management. ASEAN Foundation, Jakarta.

[11] Wunram, M., Thoben, K.D. and Weber, F. (2001) Toward Pragmatic Approaches for Knowledge Management in Engineering Theory and Industrial Applications. ICED2001 13 th International Conference on Engineering Design ICED01, Glasgow, 21-23 August 2001, 91-97.

[12] Carillo, P.M., Robinson, H.S., Al-Ghassani, A.M. and Anumba, C.J. (2004) Knowledge Management in U.K. Construction: Strategies, Resources and Barriers. Project Management Journal, 35, 46-56. https://doi.org/10.1177/875697280403500105

[13] Dainty, A.R.J., Bryman, A. and Price, A. (2002) Empowerment within the U.K. Construction Sector. Leadership and Organisational Development Journal, 23, 333-342. https://doi.org/10.1108/01437730210441292

[14] Robinson, H.S., Carillo, P.M., Anumba, C.J. and Al-Ghassani, A.M. (2001) Perception and Barriers in Implementing Knowledge Management Strategies in Large Construction Organization. Foundation Construction and Building Research Conference (COBRA), Glasgow, 3-5 September 2001, 451-460

[15] Hackman, J.K., Agyekum, K. and Smith, B. (2017) Challenges to the Adoption of Knowledge Management in Civil Engineering Construction Firms in Ghana. Annals of Faculty Engineering Hunedoara-International Journal of Engineering, 1, 87-95.

[16] Asoh, D., Belardo, S. and Neilson, R. (2002) Knowledge Management: Issues, Challenges and Opportunities for Governments in the New Economy. Proceedings of the 35th Hawaii International Conference on System Sciences, Big Island, HI, 7-10 January 2002, 1745-1754. https://www.computer.org/csdl/proceedings/hicss/2002/1435/05/14350129b.pdf

[17] Wong, K.Y. and Aspinwall, E. (2004) Knowledge Management Implementation Frameworks: A Review. Knowledge and Process Management, 11, 93-104. https://doi.org/10.1002/kpm.193

[18] Wetherall, M., Rezgui, Y., Lima, C. and Zarli, A. (2002) Knowledge Management for the Construction Industry: The e-COGNOS Project. ITcon, 7, 183-196.

[19] O’Dell, C. and Grayson, C.J. (1998) If Only We Knew What We Know: The Transfer of Internal Knowledge and Best Practices. The Free Press, New York.

[20] Guribie, F.L., Tengan, C. and Kuebutornye, N.D.K. (2018) Knowledge Management Practice in the Ghanaian Construction Industry: A Case Study of 4 Firms in the Tamale Metropolis. Information and Knowledge Management, 8, 83-88.

[21] Venkatesh, V. and Davis, F.D. (2000) A Theoretical Extension of the Technology Acceptance Model: Four Longitudinal Field Studies. Management Science, 46, 186-204. https://doi.org/10.1287/mnsc.46.2.186.11926

[22] Mpofu, R.T. (2011) Knowledge Management Practices in Malawi. African Journal of Business Management, 5, 12408-12417.

[23] Davis, F.D. (1989) Perceived Usefulness, Perceived Ease of Use, and User Acceptance of Information Technology. MIS Quarterly, 13, 319-340.

https://doi.org/10.2307/249008 